\title{
Friction and Wear Behavior of Micro Arc Oxidation Coatings on Magnesium Alloy at High Temperature
}

\author{
Jin Jie, Li Huan, Li Xiaohan \\ Zhejiang University of Technology, Hangzhou 310014, China
}

\begin{abstract}
A ceramic coating was formed on AZ91D magnesium alloy by micro arc oxidation technology in aqueous solution containing silicate and phosphate. The phase composition, surface, cross-sectional and wear tracks morphologies of the coating were analyzed by XRD, SEM and Laser Scanning Confocal Microscope (LSCM), respectively. UMT-3 High Temperature Tribometer was used to study the friction and wear behaviors of coating within $150^{\circ} \mathrm{C}$. The results show that the coatings' mean friction coefficient firstly increases with the temperature increasing. When the ambient temperature exceeds $100^{\circ} \mathrm{C}$, it begins to reduce. The wear rate of the coating is much lower than that of magnesium alloy substrate, and it declines as temperature goes up. The results indicate that the micro arc oxidation coating has excellent wear resistance particularly at high temperature. Through the analysis of grinding cracks' micro-structure at the load of $2 \mathrm{~N}$, the main wear mechanism of these coatings at different temperatures is all abrasive wear.
\end{abstract}

Key words: magnesium alloy; micro arc oxidation; high temperature; friction and wear behaviors

Magnesium alloys research focuses on auto parts in energy saving and emission reduction fields due to their low density, high specific strength and high energy attenuation coefficient. While the poor wear resistance and corrosion resistance of magnesium alloys owing to their low hardness and high chemical activity restrict their wide application in auto industry $^{[1-4]}$

In recent years, micro arc oxidation (MAO) has been widely used in magnesium alloys surface modification. It is a potential technology that can effectively improve magnesium alloys' wear resistance and corrosion resistance ${ }^{[5-7]}$. The process is that in the electrolyte of certain composition, using magnesium alloy as the anode, stainless steel container as the cathode, one applies pulse high voltage and high current between the electrodes; then the magnesium alloy surface produces micro arc discharge, and a kind of oxide ceramic coating with good adhesion, excellent corrosion resistance and wear resistance in situ grows in the surface ${ }^{[8,9]}$.

At present, many researchers have studied the friction and wear performances of micro arc oxidation coatings on magnesium alloys at room temperature ${ }^{[10-15]}$, but the wear performances at higher temperature are rarely reported. According to a Ref.[16], magnesium alloys crystal sliding trend becomes active and their mechanical strength declines when temperature exceeds $450 \mathrm{~K}$ (about $150^{\circ} \mathrm{C}$ ), so they are usually used that temperature. Therefore the present work was undertaken to investigate the coatings' friction and wear properties within the condition of $150^{\circ} \mathrm{C}$ and could provide experimental and theoretical bases for the applications of the coatings at higher temperature.

\section{Experiment}

AZ91D magnesium alloy, whose chemical composition was given in Table 1, was used as substrate material. The size of samples were all $\Phi 50 \mathrm{~mm} \times 2 \mathrm{~mm}$. Before micro arc oxidation, the samples were drilled at first and then were polished with $180 \# \sim 800 \#$ CW waterproof abrasive papers and cleaned using acetone ultrasonic for $15 \mathrm{~min}$. At last the samples were washed with deionized water and dried with a drier. MAO process was carried out with a MAO device (DSM35F) invented by Harbin University of Technology. The samples and stainless steel container were used as anode and cathode, 
Table 1 Nominal chemical composition of AZ91D (wt\%)

\begin{tabular}{ccccccc}
\hline $\mathrm{Al}$ & $\mathrm{Zn}$ & $\mathrm{Mn}$ & $\mathrm{Si}$ & $\mathrm{Cu}$ & $\mathrm{Ni}$ & $\mathrm{Mg}$ \\
\hline 9.5 & 0.90 & 0.40 & $\leqslant 0.05$ & $\leqslant 0.025$ & $\leqslant 0.001$ & $\mathrm{Bal}$. \\
\hline
\end{tabular}

respectively. The electrolyte was prepared by dissolution of reagent grade chemicals of sodium silicate $(10 \mathrm{~g} / \mathrm{L})$, sodium phosphate $(10 \mathrm{~g} / \mathrm{L})$, sodium hydroxide $(8 \mathrm{~g} / \mathrm{L})$ and some additions. With a constant current mode, the current density, frequency, duty cycle and process time were $20 \mathrm{~A} / \mathrm{dm}^{2}, 800$ $\mathrm{HZ}, 20 \%$ and $15 \mathrm{~min}$, respectively. The electrolyte's temperature was kept below $20^{\circ} \mathrm{C}$ with a cooling system.

Tribological properties of coatings at high temperatures were investigated by a ball-on-disc high temperature tribo tester (UMT-3). The experiments were conducted with a $\mathrm{Si}_{3} \mathrm{~N}_{4}$ ball with the diameter of $9.5 \mathrm{~mm}$ in sliding contact. The tests were implemented at room temperature, 75, 100, 125 and $150{ }^{\circ} \mathrm{C}$ under a load of $2 \mathrm{~N}$ at the speed of $200 \mathrm{r} / \mathrm{min}$ and in dry sliding condition. The wear tracks radius of magnesium alloy and the coatings were $5 \mathrm{~mm}$ and the tests were performed for $10 \mathrm{~min}$. The wear tracks morphologies and wear volume of magnesium alloy and coatings were observed and calculated, respectively by the Laser Scanning Confocal Microscope (LSM700). The wear rate was calculated using $K=V / F L$ equation, where $K$ is the value of wear rate, $V$ is the worn volume, $F$ is the normal load, $L$ is the total length of wear track.

The phases of magnesium alloy and coatings before and after tribological tests were analyzed through X-ray diffractometer equipment ( $\mathrm{X}^{\prime}$ PertPro) with a $\mathrm{Cu} \mathrm{K} \alpha$ radiation source. The scanning angle was $10^{\circ} \sim 80^{\circ}$. The morphology of surface, cross section and wear tracks were observed by a scanning electron microscope (SEM-VEGA3) and the composition of coating and wear debris was analyzed by Energy Disperse Spectroscopy (EDS).

\section{Results and Discussion}

\subsection{XRD analysis}

XRD patterns for magnesium alloy and the coating are shown in Fig.1. The coating is mainly composed of $\mathrm{MgO}$ phase (Periclase, syn) and $\mathrm{Mg}_{2} \mathrm{SiO}_{4}$ phase (Forsterite, syn) compared with the XRD pattern of magnesium alloy. From Fig.1, magnesium phase appears in the XRD pattern of the coating as the coating is thinner. The process of micro arc oxidation produces high energy, making the surface of substrate molten, and the molten magnesium alloy could react with oxygen and silicate ions in the discharge channel, forming $\mathrm{MgO}$ phase and $\mathrm{Mg}_{2} \mathrm{SiO}_{4}$ phase respectively. Those phases could effectively improve the hardness of magnesium alloy. According to the elementary composition in Table $2, \mathrm{O}$ and $\mathrm{Mg}$ elements are the main elements in the coating. While the elements of $\mathrm{Na}, \mathrm{Si}, \mathrm{P}$ and $\mathrm{F}$ are mainly from the electrolyte.

\subsection{Morphology and microstructure of the coating}

The surface and cross-section morphology of the coating are shown in Fig.2. Fig.2a reveals that the surface morphology of the oxidation coating is rough and porous. These special features are formed during the following process. A thin passive oxidation layer is formed on the substrate surface after the initial period, which is a breakdown under the action of arc discharge that is produced by high voltage. In addition, the arc discharge action produces high energy that could make the substrate molten and the molten substrate react with oxygen and silicate ions in the discharge channel. The product is sprayed to the surface owing to the high pressure in the discharge channel and then it is quickly cooled down when contacted with the cold electrolyte, eventually forming the porous morphology. There are still some microscopic cracks between those micro-holes. Because these holes are full of bubbles which are ionized with a large amount of energy and high internal stress, resulting in a reduction of material strength and thus causing the cracks ${ }^{[17]}$. The coating and the substrate are closely combined with each other and the combination mode is metallurgical bonding. The coating could be obviously divided into two layers. The outer layer is looser with more defects while the inner layer is denser

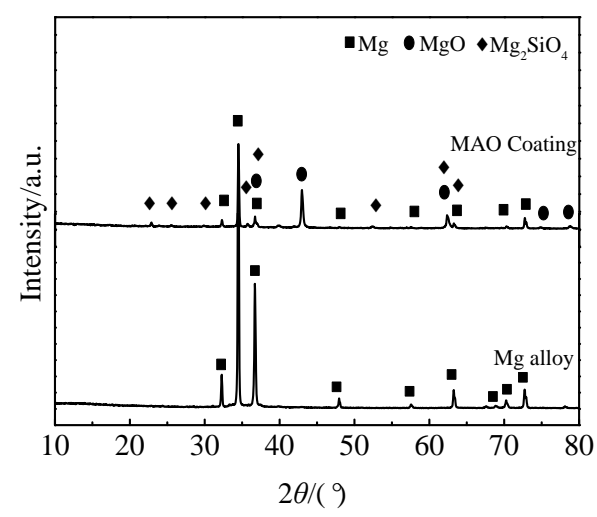

Fig. 1 XRD patterns of MAO coating and magnesium alloy

Table 2 Main elementary composition of coating on Mg alloy

\begin{tabular}{ccccccc}
\hline Element & $\mathrm{O}$ & $\mathrm{Mg}$ & $\mathrm{Na}$ & $\mathrm{Si}$ & $\mathrm{P}$ & $\mathrm{F}$ \\
\hline Content/wt\% & 34.12 & 34.96 & 5.42 & 5.88 & 1.85 & 3.16 \\
\hline
\end{tabular}
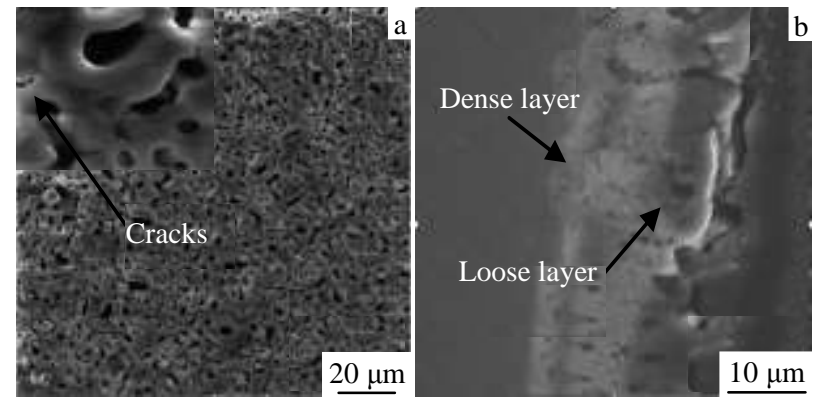

Fig.2 Surface (a) and cross-sectional (b) morphology of MAO 
coatings

with less defects.

\subsection{Friction and wear properties of magnesium alloy and coatings}

XRD patterns of coatings after tests at different temperatures are shown in Fig.3. From Fig.3 we could know that there are no considerable distinctions of the peaks after tests. The diffraction peaks of magnesium phase slightly decreases at $150{ }^{\circ} \mathrm{C}$ owing to the oxidation on coatings surface. Therefore, the XRD analysis results show that ambient temperature has little effect on the coatings phases.

Fig.4 shows the variation of friction coefficient of magnesium alloy and coatings with test time in dry sliding condition. The substrate and the coatings' average friction coefficient and wear rate $(K)$ are shown in Table 3.

For magnesium alloy at room temperature, the friction coefficient fluctuates between 0.3 and 0.5. The mean friction coefficient is 0.32 . For the coating at room temperature, the friction coefficient gradually increases to 0.5 and maintains stability for a period of time, and then it decreases to 0.48 at 80 $\mathrm{s}$ and later rises slowly with test time. For the coating at $100^{\circ} \mathrm{C}$, the friction coefficient rises sharply to 0.7 , afterward it increases slowly and at $200 \mathrm{~s}$ it begins to decline. Under the condition of

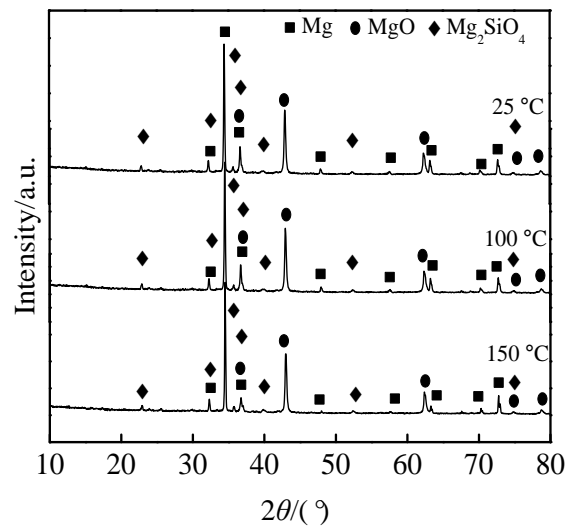

Fig.3 XRD patterns of coatings after wear tests at different temperatures

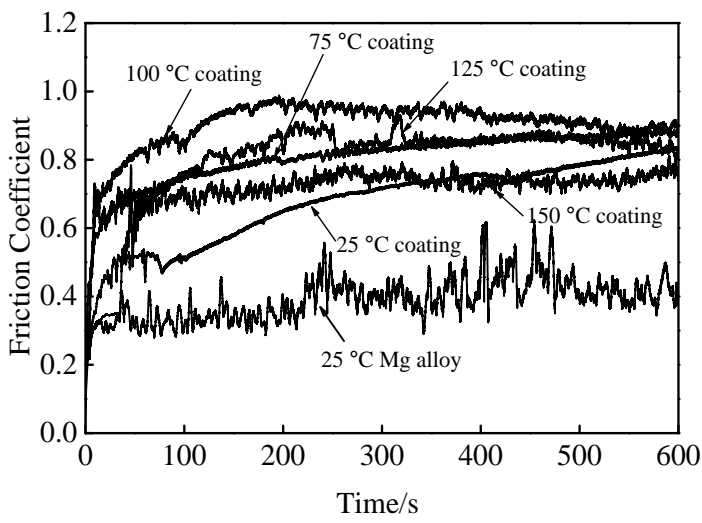

Fig.4 Variation of friction coefficients of magnesium alloy and coatings versus sliding time

$150^{\circ} \mathrm{C}$, the friction coefficient also goes upward quickly with time; when it is up to 0.7 , it begins to keep constant over time. The highest average friction coefficient $(0.90)$ is obtained at $100^{\circ} \mathrm{C}$. The coatings' friction coefficient increasing at different temperatures is resulted from the hard wear abrasive effect. When the environment temperature is below $100^{\circ} \mathrm{C}$, localized friction heat could increase the thermal stress of the coating, leading micro-cracks to expand. It destroys the surface defect area and forms a lot of debris, while more wear debris are helpful to increase the friction coefficient. When ambient temperature exceeds $100^{\circ} \mathrm{C}$, localized friction heat is hard to dissipate and the local temperature was too high, the excessive heat decreases the contact surfaces' hardness and shear force of friction pair ${ }^{[13]}$; it makes the surface more smooth in the test process which is helpful to reduce the friction coefficient. According to Table 3, the wear rate of magnesium alloy is much higher than that of the coatings, so micro arc oxidation coatings have excellent wear resistance.

Fig.5 shows the wear tracks morphologies of magnesium alloy and oxidation coatings. After the friction and wear test, the wear track width of magnesium alloy is about $1 \mathrm{~mm}$, which is wider than that of the coatings. The tracks widths at 100 and $150{ }^{\circ} \mathrm{C}$ are nearly 0.2 and $0.3 \mathrm{~mm}$ respectively and they are relatively narrow compared to the coating's wear track width at room temperature. The two dimensional profiles of wear tracks

Table 3 Mean friction coefficients and wear rate $K$ of magnesium alloy and coatings at different temperatures

\begin{tabular}{cccc}
\hline Specimen & $T{ }^{\circ} \mathrm{C}$ & Mean coefficient & $K / \times 10^{-7} \mathrm{~mm}^{3} \cdot(\mathrm{N} \cdot \mathrm{mm})^{-1}$ \\
\hline Substrate & 25 & 0.32 & 27.40 \\
Coating & 25 & 0.68 & 2.81 \\
Coating & 75 & 0.81 & 1.19 \\
Coating & 100 & 0.90 & 0.35 \\
Coating & 125 & 0.80 & 0.30 \\
Coating & 150 & 0.72 & 0.24 \\
\hline
\end{tabular}

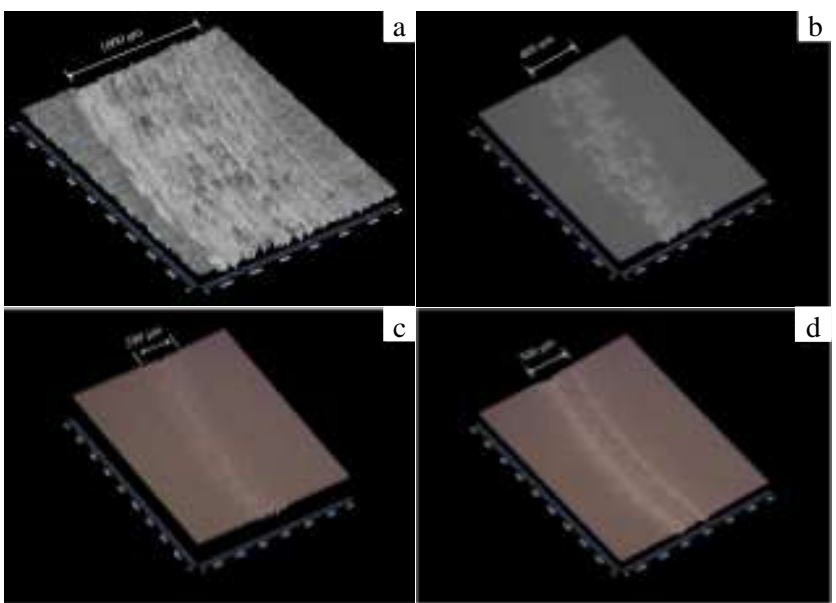

Fig.5 Wear tracks morphologies of magnesium alloy and coatings: (a) $25^{\circ} \mathrm{C}$ substrate, (b) $25^{\circ} \mathrm{C}$ coating, (c) $100^{\circ} \mathrm{C}$ coating, and 
(d) $150{ }^{\circ} \mathrm{C}$ coating

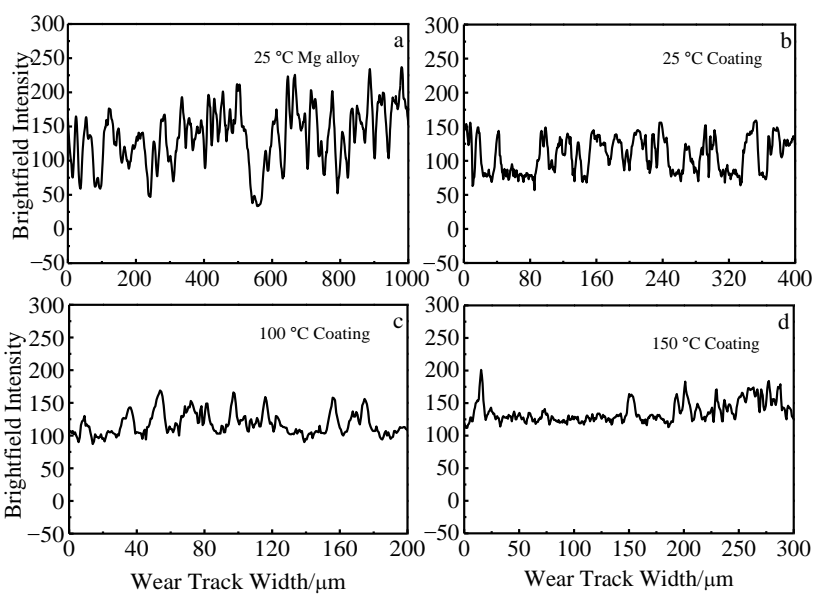

Fig.6 Two dimensional profiles of the wear tracks for magnesium alloy and coatings: (a) $25^{\circ} \mathrm{C}$ substrate, (b) $25^{\circ} \mathrm{C}$ coating, (c) $100^{\circ} \mathrm{C}$ coating, and (d) $150^{\circ} \mathrm{C}$ coating

are shown in Fig.6. The brightfield intensity could reflect the depth of wear track surface. For the wear track of magnesium alloy, the intensity fluctuates strongly which means that the grinding crack of the substrate is deep and rough owing to its low hardness. Because the ceramic coating is relatively harder, it could protect the substrate from abrasion wear to gain the shallow wear depth. The depth of the coating' grinding crack is relatively shallower at $150{ }^{\circ} \mathrm{C}$, since the condition of the friction pair's contact surface is improved at high temperature. Combined Table 3, Fig.5 with Fig.6, we could obtain that micro arc oxidation technology could efficiently improve the wear resistance of magnesium alloy especially at high temperature. The wear rate of the coating at $150{ }^{\circ} \mathrm{C}$ is lowest which indicates the coating at high temperature condition has better wear resistance. According to the results we reaches a conclusion that micro arc oxidation technology could give more application chances for magnesium alloys at high temperature.

The wear tracks morphologies of magnesium alloy and coatings at different temperatures are shown in Fig.7. An obvious furrow topography appears on the magnesium alloy surface with a mass of granular wear debris. The formation of furrow track is attributed to the lower hardness of substrate compared to the $\mathrm{Si}_{3} \mathrm{~N}_{4}$ ceramic ball, the micro convex parts of the ceramic ball plough the substrate and produce a large number of wear debris in the process of test. Besides, parts of wear debris generate hard magnesium oxide particles under the action of frictional heat in the process of test inducing the substrate to produce more wear debris ${ }^{[18]}$. Therefore, the magnesium alloy mainly produces oxidation wear, abrasive wear and plough wear in the process of wear test. According to Fig. $7 b \sim 7 d$, it is suggested that at different temperatures, parts of micro arc oxidation holes of coatings' surface are filled with a large number of fine particulate wear debris. At $150{ }^{\circ} \mathrm{C}$ more fine wear debris fill the holes defects making the wear track surface dense and smooth which could reduce further wear

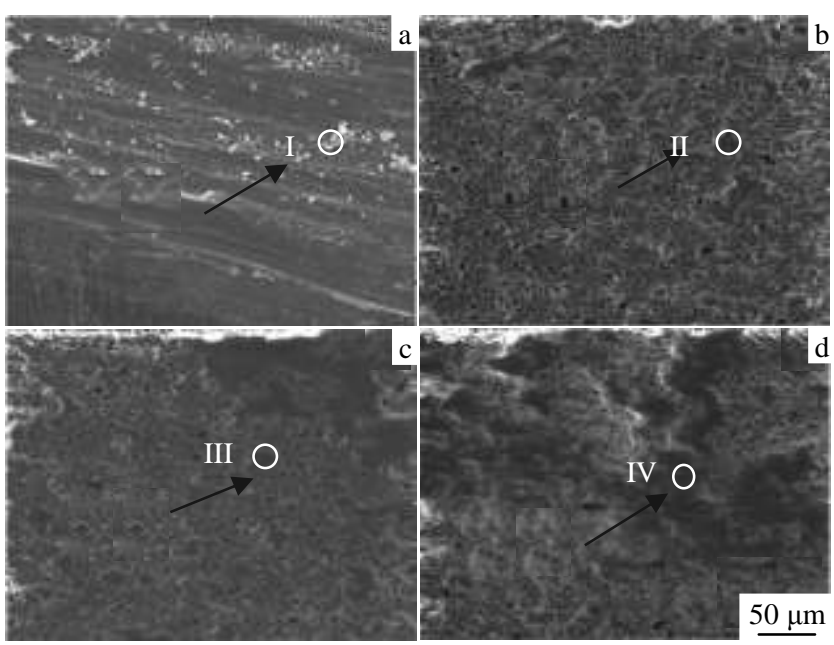

Fig.7 Wear tracks topography of magnesium alloy and coatings: (a) $25^{\circ} \mathrm{C}$ substrate, (b) $25^{\circ} \mathrm{C}$ coating, (c) $100^{\circ} \mathrm{C}$ coating, and (d) $150^{\circ} \mathrm{C}$ coating

Table 4 EDS analysis results of the marked regions (wear debris) in Fig. 7 (wt\%)

\begin{tabular}{ccccc}
\hline Region & $\mathrm{Mg}$ & $\mathrm{O}$ & $\mathrm{Si}$ & $\mathrm{P}$ \\
\hline I & 99.19 & 8.21 & - & - \\
II & 36.89 & 32.74 & 5.85 & 1.59 \\
III & 37.71 & 35.79 & 6.16 & 1.97 \\
IV & 40.03 & 35.88 & 6.14 & 1.75 \\
\hline
\end{tabular}

debris production and help to improve wear resistance. From the results of EDS analysis (Table 4), the main constituents of wear debris were $\mathrm{Mg}$ and $\mathrm{O}$ elements. Those elements are also the main composition of the coating and their contents are close to the coating's (seen from Table 2). So it could be concluded that the wear debris mainly come from the ceramic coatings and the wear mechanism of micro arc oxidation coatings under different temperatures is abrasive wear.

\section{Conclusions}

1) The ceramic coating on AZ91D magnesium alloy by micro arc oxidation technology in aqueous solution containing silicate and phosphate is mainly composed of $\mathrm{MgO}$ phase and $\mathrm{Mg}_{2} \mathrm{SiO}_{4}$ phase. The oxidation coating's surface is rough and porous. The combination mode between coating and substrate is metallurgical bonding. The coating could be obviously divided into two layers. The outer layer was looser with more defects while the inner layer is denser with less defects.

2) Micro arc oxidation technology could significantly improve the wear resistance of magnesium alloys and the coatings' wear resistance at higher temperature is superior to that at colder temperature. At a certain load, the magnesium alloy substrate mainly produces oxidation wear, abrasive wear and plough wear, while the coatings' wear mechanism under 
different temperature is all abrasive wear.

\section{References}

1 Jun Liang, Li Tianhu, Jing Chenghao. Applied Surface Science[J], 2007, 253: 490

2 Wang Qudong, Lu Yizhen, Zeng Xiaole. Material Reviews[J], 2000, 14: 22 (in Chinese)

3 Kulerkci M K. International Journal Advanced Manufacturing Technology[J], 2008, 39: 851

4 Yue Yang, Hua Wu. Material Science and Technology[J], 2010, 26: 865

5 Demirci E E, Arslan E, Ezirmik K V et al. Thin Solid Films[J], 2013, 528: 116

6 Jiang Bailing, Zhang Shufang, Wu Guojian. Journal of Chinese Society for Corrosion and Protection[J], 2002, 22: 300

7 Chen Fei, Zhou Hai, Yao Bin et al. Rare Metal Materials and Engineering [J], 2006, 35(5): 806 (in Chinese)

8 Jiang Bailing, Zhang Xianfeng. Rare Metal Materials and Engineering [J], 2005, 34(3): 393 (in Chinese)

9 Guo Huixia, Ma Ying, Zhang Yufu et al. Journal of the Chinese
Ceramic Society[J], 2013, 41: 382

10 Guo Jie, Liang Jun, Yan Fengyuan et al. Chemical Research[J], 2009, 20: 59

11 Durdu S, Usta M. Applied Surface Science[J], 2012, 261: 774

12 Peng Jihua, Huang Fangliang, Liu Gang et al. The Chinese Journal of Nonferrous Metals[J], 2009, 19: 981 (in Chinese)

13 Huang Weijiu, Liu Ming. Material and Heat Treatment[J], 2007, 36: 44 (in Chinese)

14 Hu Huiling, Wu Xiangqing, Xie Faqing et al. Material and Heat Treatment $[\mathrm{J}], 2011,40: 128$ (in Chinese)

15 Gao Ningning, Wang Yawei, Hu Huili. Plating \& Finishing $[\mathrm{J}]$, 2009, 31: 17

16 Kausi D L, Yan Kun, Mark R. Materials Science \& Engineering $A[\mathrm{~J}], 2014,601: 78$

17 Jiang Bailing, Xia Tian, Shi Huiying et al. Transactions of Materials and Heat Treatment[J], 2005, 26: 82

18 Ma Chunxiang, Zhang Milin, Yuan Yi et al. Tribology International[J], 2012, 47: 62

\section{镁合金微弧氧化涂层高温磨擦磨损性能}

金 杰, 李 欢, 李晓涵

(浙江工业大学, 浙江 杭州 310014)

摘 要: 在硅酸盐和磷酸盐复合电解液体系下, 通过微弧氧化技术在 AZ91D 镁合金表面制备一层陶瓷涂层。利用 XRD、SEM、激光共 聚焦显微镜 (LSCM) 分别对涂层物相、涂层表面、截面和磨痕形貌进行观察分析。采用 UMT-3 高温摩擦磨损试验机研究涂层在 $150{ }^{\circ} \mathrm{C}$ 范围内的摩擦磨损性能。结果表明: 涂层的平均摩擦系数随温度的变化先逐渐升高, 当环境温度高于 $100{ }^{\circ} \mathrm{C}$ 时涂层平均摩擦系数开始降 低。涂层磨损率远远低于镁合金基体磨损率并且涂层磨损率随温度的升高而降低，这说明微弧氧化涂层具有良好的耐磨损性能，尤其在 高温条件下耐磨损性能更好。通过分析载荷为 $2 \mathrm{~N}$ 作用时的磨痕微观形貌可知不同温度条件下涂层的磨损机理都主要为磨粒磨损。

关键词: 镁合金; 微弧氧化; 高温; 摩擦磨损性能

作者简介：金 杰, 男, 1960 年生, 博士，教授，浙江工业大学材料科学与工程学院，浙江 杭州 310014, E-mail: bluejinjie@ 126.com 